\title{
Clonal Analysis of Staphylococcus aureus Strains Isolated in Obstetric-Gynaecological Hospital
}

\author{
EWA SZCZUKA ${ }^{1}$, ANNA SZUMAŁA-KĄKOL $^{2}$, ANNA SIUDA $^{1}$ and ADAM KAZNOWSKI ${ }^{1 *}$ \\ ${ }^{1}$ Department of Microbiology, Institute of Experimental Biology, Faculty of Biology, Adam Mickiewicz University, \\ Umultowska 89, 61-614 Poznań, Poland \\ ${ }^{2}$ Hospital Laboratories, Obstetric-Gynaecological Clinical Hospital, Polna 33, 60-535 Poznań, Poland
}

Received 1 December 2009, revised 16 June 2010, accepted 17 June 2010

\begin{abstract}
Epidemiological studies were carried out on 135 isolates of Staphylococcus aureus strains originating from medical staff, patients, and hospital environment. Restriction fragment length polymorphism (RFLP) analysis revealed genetic diversity of $S$. aureus isolates. Some clones were transmitted among nurses, doctors and patients. Our studies also demonstrate contamination of the hospital environment with $S$. aureus strains and there is a possibility that the patients acquire staphylococci from the environment. Moreover, we found that many medical staff workers were colonized with $S$. aureus and the transmission of these strains to patients is possible.
\end{abstract}

Ke y w ord s: Staphylococcus aureus, epidemiological studies, RFLP analysis

\section{Introduction}

Staphylococcus aureus has been recognised as an important pathogen causing many infections such as septicemia, pneumonia, wound infections, septic arthritis, osteomyelitis and postsurgical toxic shock syndrome (Kloos and Bannerman, 1999). On the other hand, many healthy people are persistently or intermittently colonized with $S$. aureus at their anterior nares. Approximately $20 \%$ of individuals almost always carry one type of strain, $60 \%$ harbor $S$. aureus intermittently. About $20 \%$ of people almost never carry S. aureus. Colonization of human noses by $S$. aureus appears to play a role in the epidemiology and pathogenesis of infection (Kluytmans et al., 1997). S. aureus is one of leading agents of nosocomial infections therefore for public health epidemiologists and clinicians involved in patient management of prime importance is understanding the dynamics of the spread and transmission the of bacteria within a hospital, this being crucial for their control and eradication. Molecular typing approaches have been used to a great advantage in identifying and monitoring the local and international spread of $S$. aureus strains (Štěpán et al., 2004).
The aim of the present study was to evaluate the clonal composition of Staphylococcus aureus strains isolated from specimens taken from patients, medical staff and hospital environment at the ObstetricGynaecological Clinic Hospital in Poznań, Poland. Moreover, we wanted to elucidate the spread of clones in different departments and the possible transmission routes of these clones.

\section{Experimental}

\section{Material and Methods}

Bacterial strains. S. aureus strains were isolated from clinical specimens obtained from neonates and adult patients treated in different medical units in a hospital in Poznań. Several members of the healthcare staff were screened for S. aureus nasal, throat and hand carriage. Also specimens from medical equipment and hospital environment were taken. All strains were identified as $S$. aureus by analysis of cell morphology, Gram stain, and catalase production, using the latex coagulase test and the ID 32 Staph Kit (bioMérieux, France). Methicillin susceptibility test

\footnotetext{
* Corresponding author: A. Kaznowski, Department of Microbiology, Faculty of Biology, A. Mickiewicz University,
} ul. Umultowska 89, 61-614 Poznań, Poland; phone (+48) 61529 5937; fax (+48) 61829 5590; e-mail: akazn@amu.edu.pl 

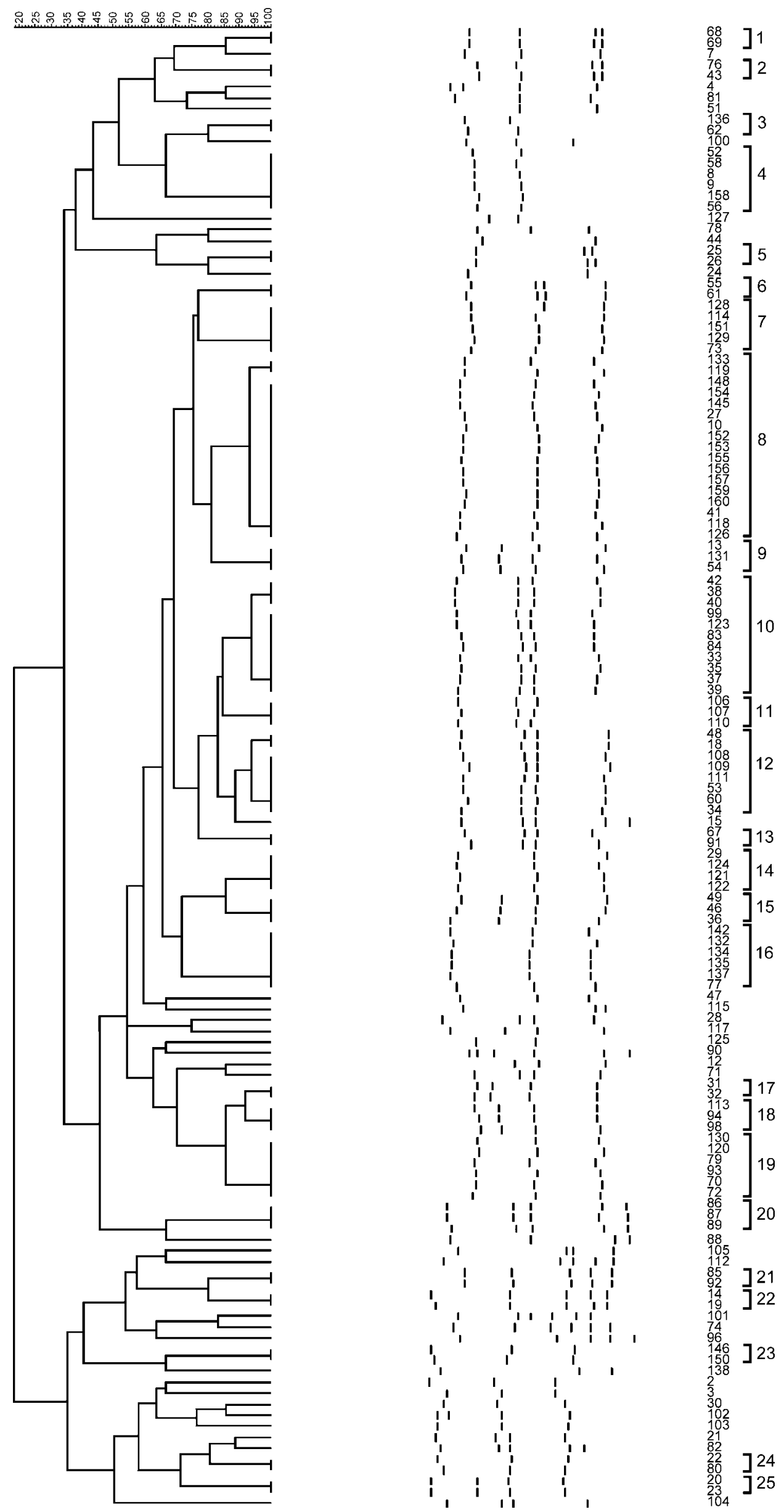

Fig. 1. Dendrogram showing genetic relatedness of 135 strains of $S$. aureus determined by analysis of RFLP fingerprint patterns using Dice similarity coefficient and UPGMA cluster method. 
was determined by disc diffusion method and the results were interpreted in accordance to the criteria of the Clinical Laboratory Standards. The presence of the mecA gene was determined by PCR as described previously (Geha et al., 1994).

RFLP analysis. Chromosomal DNA from the S. aureus strains were extracted according to methods described by Pitcher et al. (1989). A PCR was applied to simultaneously amplified part of the hypervariable region (HVR), a part of spa gene and a part of the coa gene based on primers established by Wichelhaus et al., 2001. The PCR product was incubated overnight with 10 units of HaeII restriction enzyme (MBI Fermentas) at $37^{\circ} \mathrm{C}$. The resulting fragments were separated in $1.5 \%$ agarose gel. The DNA in gels were documented with V.99 Bio-Print system (Vilber Lourmat, Torcy, France). A computer analysis was carried out using GelCompar II (version 3.0; Applied Maths, Kortrijk, Belgium) software. Similarity between fingerprints was calculated with the Dice coefficient. Cluster analysis was performed using the unweighted pair-group method with average linkages (UPGMA).

\section{Results and Discussion}

All strains included in this study were methicillin/ oxacillin sensitive phenotypically and did not harbour the mecA gene. Our results demonstrated that many clones of $S$. aureus were coexisting in one hospital. This conclusion is based upon the results generated by clonal analysis of 135 strains of $S$. aureus (Fig. 1). We revealed 25 clusters at the $90 \%$ similarity level (Table I). Strains within these clusters were considered to be genetically related. We identified three major clones (cluster 8,10, and 12), which included $28 \%$ strains of $S$. aureus. As shown in the dendrogram, there are five smaller clusters consisting from six to four strains. In addition, we found a considerable number of minor clusters, each harboring three or two strains. Minor clusters reached 36 strains (29\%). Moreover, we identified 32 single strains with unique genotypes. The fact, that 25 clusters were identified next to 32 unique genotypes indicating a large genetic diversity among isolates of $S$. aureus obtained from the hospital. Similar result was obtained previously by Van Dijk et al., 2002, who described genetic diversity among $S$. aureus isolates from a Dutch Teaching Hospital.

Although S. aureus has been described as the normal flora of nasal carriage, several epidemiological studies indicated that nasal carriage have increased risk for staphylococcal infections especially in specific group of patients (Archer and Climo 2001; KooistraSmid et al., 2004; Melless et al., 2004). Staphylococcus sp. infections are most commonly acquired from
Table I

Results of $S$. aureus clinical isolate typing by using RFLP analysis

\begin{tabular}{|c|c|c|}
\hline $\begin{array}{l}\text { Clu- } \\
\text { ster }\end{array}$ & Strain No & Source of isolation \\
\hline 1 & MPU S 68, 69 & nasal swab of medical staff \\
\hline 2 & $\begin{array}{l}\text { MPU S } 43 \\
\text { MPU S } 76\end{array}$ & $\begin{array}{l}\text { clothes of medical staff } \\
\text { throat swab of medical staff }\end{array}$ \\
\hline 3 & MPU S 62, 136 & throat swab of medical staff \\
\hline 4 & $\begin{array}{l}\text { MPU S } 8,9 \\
\text { MPU S 52, 58, } 56 \\
\text { MPU S } 158\end{array}$ & $\begin{array}{l}\text { abscess of neonates } \\
\text { nasal swab of medical staff } \\
\text { hand basin }\end{array}$ \\
\hline 5 & $\begin{array}{l}\text { MPU S } 25 \\
\text { MPU S } 26 \\
\end{array}$ & $\begin{array}{l}\text { throat swab of medical staff } \\
\text { hands of medical staff }\end{array}$ \\
\hline 6 & MPU S 55, 61 & nasal swab of medical staff \\
\hline 7 & $\begin{array}{l}\text { MPU S 73, } 128 \\
\text { MPU S } 114,151 \\
\text { MPU S } 129\end{array}$ & $\begin{array}{l}\text { throat swab of medical staff } \\
\text { wound of patient } \\
\text { patient's bed }\end{array}$ \\
\hline 8 & $\begin{array}{l}\text { MPU S } 10,126,133, \\
152,155 \\
\text { MPU S } 27,41 \\
\text { MPU S } 118,156,119, \\
145,148 \\
\text { MPU S } 153,160 \\
\text { MPU S } 154 \\
\text { MPU S } 157 \\
\text { MPU S } 159\end{array}$ & $\begin{array}{l}\text { throat swab of medical staff } \\
\text { clothes of medical staff } \\
\text { nasal swab of medical staff } \\
\text { patient's bed } \\
\text { hand basin } \\
\text { vagina of patient } \\
\text { throat swab of neonate }\end{array}$ \\
\hline 9 & $\begin{array}{l}\text { MPU S 13,54 } \\
\text { MPU S } 131\end{array}$ & $\begin{array}{l}\text { throat swab of medical staff } \\
\text { skin of neonate }\end{array}$ \\
\hline 10 & $\begin{array}{l}\text { MPU S 33, 39, 42, 83, } 99 \\
\text { MPU S } 35,84 \\
\text { MPU S } 37,38 \\
\text { MPU S } 40 \\
\text { MPU S } 123 \\
\end{array}$ & $\begin{array}{l}\text { clothes of medical staff } \\
\text { nasal swab of medical staff } \\
\text { hands of medical staff } \\
\text { skin of neonate } \\
\text { scale in delivery room }\end{array}$ \\
\hline 11 & MPU S 106 & hand basin \\
\hline & MPU S 107 & abscess of patient \\
\hline & MPU S 110 & clothes of medical staff \\
\hline 12 & $\begin{array}{l}\text { MPU S } 18,48,108 \\
\text { MPU S } 34,53 \\
\text { MPU S } 60 \\
\text { MPU S } 109 \\
\text { MPU S } 111 \\
\end{array}$ & $\begin{array}{l}\text { nasal swab of medical staff } \\
\text { throat swab of medical staff } \\
\text { abscess of neonate } \\
\text { vagina of patient } \\
\text { hands of medical staff }\end{array}$ \\
\hline 13 & MPU S 67, 91 & patient's bed \\
\hline 14 & $\begin{array}{l}\text { MPU S } 29 \\
\text { MPU S } 121 \\
\text { MPU S } 122,124 \\
\end{array}$ & $\begin{array}{l}\text { throat swab of medical staff } \\
\text { hand basin } \\
\text { patient's bed }\end{array}$ \\
\hline 15 & $\begin{array}{l}\text { MPU S } 36 \\
\text { MPU S 46, } 49\end{array}$ & $\begin{array}{l}\text { clothes of medical staff } \\
\text { skin of neonate }\end{array}$ \\
\hline 16 & $\begin{array}{l}\text { MPU S } 77,142 \\
\text { MPU S } 132,135 \\
\text { MPU S } 134 \\
\text { MPU S } 137\end{array}$ & $\begin{array}{l}\text { hand basin } \\
\text { patient's bed } \\
\text { catheter of neonate } \\
\text { nasal swab of medical staff }\end{array}$ \\
\hline 17 & $\begin{array}{l}\text { MPU S } 31 \\
\text { MPU S } 32\end{array}$ & $\begin{array}{l}\text { nasal swab of medical staff } \\
\text { hands of medical staff }\end{array}$ \\
\hline 18 & $\begin{array}{l}\text { MPU S } 94 \\
\text { MPU S } 98 \\
\text { MPU S } 113 \\
\end{array}$ & $\begin{array}{l}\text { hand basin } \\
\text { patient's bed } \\
\text { vagina of patient }\end{array}$ \\
\hline 19 & $\begin{array}{l}\text { MPU S 70, 72, } 130 \\
\text { MPU S } 79 \\
\text { MPU S } 93 \\
\text { MPU S } 120\end{array}$ & $\begin{array}{l}\text { nasal swabs of medical staff } \\
\text { hands of medical staff } \\
\text { patient's bed } \\
\text { scale }\end{array}$ \\
\hline
\end{tabular}


Table I continued

\begin{tabular}{|l|l|l|}
\hline $\begin{array}{c}\text { Clu- } \\
\text { ster }\end{array}$ & \multicolumn{1}{|c|}{ Strain No } & \multicolumn{1}{|c|}{ Source of isolation } \\
\hline 20 & $\begin{array}{l}\text { MPU S 86, 87 } \\
\text { MPU S 89 }\end{array}$ & $\begin{array}{l}\text { medical equipment } \\
\text { nasal swab of medical staff }\end{array}$ \\
\hline 21 & MPU S 85, 92 & nasal swabs of medical staff \\
\hline 22 & $\begin{array}{l}\text { MPU S 14 } \\
\text { MPU S 19 }\end{array}$ & $\begin{array}{l}\text { skin of neonate } \\
\text { hands of medical staff }\end{array}$ \\
\hline 23 & $\begin{array}{l}\text { MPU S 146 } \\
\text { MPU S 150 }\end{array}$ & $\begin{array}{l}\text { throat swab of medical staff } \\
\text { wound of neonate }\end{array}$ \\
\hline 24 & MPU S 22, 80 & nasal swab of medical staff \\
\hline 25 & $\begin{array}{l}\text { MPU S 20 } \\
\text { MPU S 23 }\end{array}$ & $\begin{array}{l}\text { nasal swab of medical staff } \\
\text { conjunctive of neonate }\end{array}$ \\
\hline
\end{tabular}

patients' own flora, however patients may become infected from other healthy carriers. It is worthy to note that $S$. aureus carriers can contaminate their clothes and their surroundings through air, dust etc. It is well known that decolonization may reduce the risk of $S$. aureus infections in carries and prevent transmission to other patients. Recently, Gilpin et al. (2010) indicated that the standard decolonization protocol did not result in long-term clearance of MRSA carriage for most patients. In this study we found that many nurses and doctors harbored and/or were colonized with $S$. aureus strains. We also found strains of $S$. aureus on nurses' hands and clothes.

We found six clusters $(4,7,8,10,11,16)$ comprising strains isolated from patients, nurses and hospital environment. It is difficult to determine exactly where and to whom transmission of $S$. aureus occurred. It is probably, that the cross-transmission of $S$. aureus occurred via hands, which may be contaminated by contact with colonized or infected body sites of medical staff or colonised or infected patient or with devises. Nurses' and doctors' hands could be contaminated by strains existing in the hospital environment. For example, cluster 4 included strains of $S$. aureus isolated from two neonates, three nurses and one strain from environment. It is important to note that these neonates suffered from skin infection. We also identified clusters $(9,12,22,23)$ that included only strains isolated from patients and medical staff. For example cluster 22 included one strain isolated from skin of neonate and one isolate originated from nurse's hands working in delivery room. Therefore, we think that the medical staff could be considered an important vector in the chain of $S$. aureus transmission. Previously, it has been reported that strains isolated from nurses' hands could be regarded as the source of staphylococcal scaled skin syndrome (SSSS) of neonates in a maternity unit in Paris (Helali et al., 2005). Similary, Bertin et al., 2006, indicated that strains isolated from a healthcare worker suffering from otitis externa and carrries Staphylococcus aureus could be responsible for the outbreak of bloodstream infections in a neonatal intensive care unit. Hand hygiene has been recognized as the key to prevent transmission of S. aureus strains and to reduce the nosocomial infections. Sroka et al. (2010) indicated that the increasing consumption of hand antiseptics was associated with a significant reduction of $S$. aureus rate.

We isolated strains from medical equipment, patients' beds or hand wash basins. Previously, several authors also demonstrated that hospital equipment and environment could be the reservoirs of $S$. aureus (Ohara et al., 1998; Embil et al., 2001; Hardly et al., 2006; Sexton et al., 2006). In addition, it is noteworthy that staphylococci can persist in clinical areas for a long period of time (Sexton et al., 2006). Recently, Aldeyab et al. (2009) indicated that environmental decontamination using detergents and hypochlorite was effective in eliminating MRSA strains from hospital environment. We identified many clusters, which grouped strains isolated from patients and hospital environment. This suggests that patients acquired $S$. aureus from the hospital environment. However, we can not exclude the possibility that patients contaminate their surrounding such as hospital beds, hand wash basins etc. We found cluster 10, which included strains isolated from neonate, from scales used to weigh neonates after birth in the delivery room. In this cluster we also found strains, which were derived from cultures originated from healthcare workers. It might be speculate that strains obtained from scales were via contaminated nurse's hands transformed on childish skin. It is well known that shared equipment in common places is an additional source of dissemination of $S$. aureus.

Our results illustrate the great genetic diversity among $S$. aureus strains in a hospital. This study also reveals contamination of hospital environment with $S$. aureus strains and the need for more effective cleaning of the hospital environment in order to eliminate reservoirs of these strains. We believed that crosstransmission events can be reduced by strict hand hygiene and other prevention procedures.

\section{Literature}

Aldeyab M.A., Mc Elnay J.C. Elshibly S.M., Hughes C.M., McDowell D., Mc Mahon A.S., Scott M.S. and M.P. Kearnej. 2009. Evaluation of the efficacy of a conventional cleaning regimen in removing methicillin-resistant Staphylococcus aureus from contaminated surface in an intensive care unit. Infect. Control. Hosp. Epidemiol. 30: 304-306.

Archer G.L. and M.W. Climo. 2001. Staphylococcus aureus bacteremia - consider the source. N. Engl. J. Med. 344: 55-56.

Bertin M.L., R.N. Vinski, S. Schmitt, C. Sabella, L. DanzigerIsakov, M. McHugh, G.W. Procop, G. Hall, S. Gordon and J. Goldfarb. 2006. Outbreak of methicillin-resistant Staphylococcus aureus colonization and infection in neonatal intensive care unit epidemiologically linked to a healthcare worker with chronic otitis. Infect. Control. Hosp. Epidemiol. 27: 581-585. 
Embil J.E., J.A. McLeod, A.M. Al.-Barrak., G.M. Thompson, F.Y. Aoki, E.J. Witwicki M.F. Stranc, A.M. Kabani, D.R. Nicoll and L.E. Nicolle. 2001. An outbreak of methicillinresistant Staphylococcus aureus on a burn unit: potential role of contaminated hydrotherapy equipment. Burns. 27: 681-688.

Geha D.J., J.R Uhl, C.A. Gustaferro and D.H. Persing. 1994. Multiplex PCR for identification of methicillin-resistant staphylococci in the clinical laboratory. J. Clin. Microbiol. 32: $1768-1772$.

Gilpin D.F., S. Small, S. Bakkshi, M.P. Kearney, C. Cardwell and M.M. Tunney. 2010. Efficacy of standard of methicillinresistant Staphylococcus aureus decolonisation protocol in routine clinical practice. J. Hosp. Infect. 75: 93-98.

Hardly K.J., B.A. Oppenheim, S. Gossain, F. Gao and P.M. Hawkey. 2006. A study of relationship between environmental contamination with methicillin-resistant Staphylococcus aureus (MRSA) and patients' acquisition of MRSA. Infect. Control. Hosp. Epidemiol. 27: 127-132.

Helali N.El., A. Carbonne, T. Naas, S. Kerneis, O. Fresco, Y. Giovangrandi, N. Fortineau, P. Nordmann and P. Astagneau. 2005. Nosocomial outbreak of staphylococccal scaled skin syndrome in neonates: epidemiological investigation and control. J. Hosp. Infect. 61: 130-131.

Kloos W.E. and T.L. Bannerman. 1999. Staphylococcus and Micrococcus. pp. 264-282. In: Murray P.R., E. Baron, M.A. Pfallen, F.C. Tenover and R. Yolken (eds). Manual of Clinical Microbiology. ASM Press, Washington, D.C.

Kooistra-Smid M., S. van Dijk, G. Beerthuizen, W. Vogels, T. van Zwet, A. van Belkum and H. Verbrugh. 2004. Molecular epidemiology of Staphylococcus aureus colonization in a burn center. Burns. 30: 27-33.
Kluytmans J., A van Belkum and H. Verbrugh. 1997. Nosal carriage of Staphylococcus aureus: Epidemiology, underlying mechanisms, and associated risks. Clin. Microbiol. Rev. 10: 505-520.

Melless D.C., R.F. Gorking, H.A. Boelens, S.V. Snijders, J.K. Peeters, M.J. Moorhouse, P.J. van der Spek, W.B. van Leeuwen, G. Simouns, H.A Verbrugh and A. van Belkum. 2004. Natural population dynamics and expansion of patogonic clones of Staphylococcus aureus. J. Clin. Investig. 114: 1732-1740. Ohara T., Y. Itoh and K. Itoh. 1998. Ultrasound instruments as possible vectors of staphylococcal infections. J. Hosp. Infect. 40: 73-77. Pitcher D.G., N.A. Saunders and R.J. Owen. 1989. Rapid extraction of bacterial genomic DNA with guanidium thiocyanate. Lett. Appl. Microbiol. 8: 151-156.

Sexton T., P. Clarke, E. O'Neill, T. Dillane and H. Humphreys. 2006. Environmental reservoirs of methicillin-resistant Staphylococcus aureus in isolation rooms: correlation with patient isolates and implications for hospital hygiene. J. Hospit. Infect. 62: 187-194. Sroka S., Gastmeier P. and E. Meyer. 2010. Impact of alcohol hand-rub use on methicillin-resistant Staphylococcus aureus: an analysis of the literature. J. Hosp. Infect. 74: 204-211.

Štepán J. R., J. Pantuček and J. Doškař. 2004. Molecular diagnostics of clinical important staphylococci. Folia Microbiol. 49: 355-386.

Van Dijk Y., C.L.C. Wielders, A.C. Fluit, A. Paauw, R.J.A. Diepersloot and E.M. Mascini. 2002. Genotyping of clinical methicillin-susceptible Staphylococcus aureus isolates in Duch Teaching Hospital. J. Clin. Microbiol. 40: 663-665.

Wichelhaus T., K-P. Hunfeld., B. Böddinghaus, P. Kraiczy, V. Schäfer and V. Brade. 2001. Rapid molecular typing of methicillin-resistant Staphylococcus aureus by PCR-RFLP. Infect. Control. Hosp. Epidemiol. 22: 294-298. 